Vladymyrov Oleksandr, Chukhraiev Nikolay, Shmorgun Andriy, Zukow Walery, Maliuta Vladimir, Chukhraieva Olena. Polyfactorial approach in rehabilitation of football players' muscles after sports injuries. Journal of Education, Health and Sport. 2022;12(1):207-215. eISSN 2391-8306. DOI http://dx.doi.org/10.12775/JEHS.2022.12.01.017 https://apcz.umk.pl/JEHS/article/view/JEHS.2022.12.01.017 https://zenodo.org/record/5878877

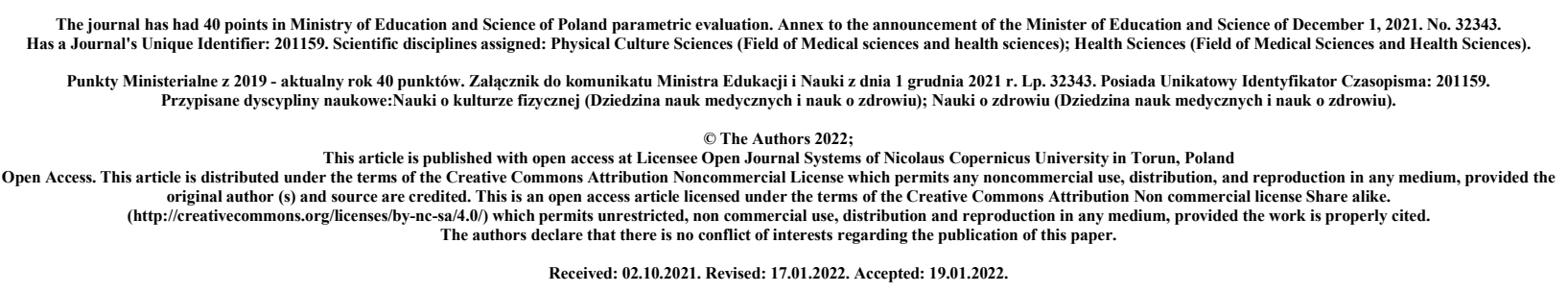

\title{
POLYFACTORIAL APPROACH IN REHABILITATION OF FOOTBALL PLAYERS' MUSCLES AFTER SPORTS INJURIES
}

\author{
Oleksandr Vladymyrov', Nikolay Chukhraiev², Andriy Shmorgun ${ }^{3}$, Walery Zukow**, \\ Vladimir Maliuta ${ }^{3}$, Olena Chukhraieva ${ }^{1}$
}

${ }^{1}$ Shupyk National Healthcare University, Kyiv, Ukraine

${ }^{2} \mathrm{SMC}$ «Medinteh», Kyiv, Ukraine

${ }^{3}$ Football Club «Dynamo Kyiv», Kyiv city, Ukraine

${ }^{4}$ Nicolaus Copernicus University, Toruń, Poland

*w.zukow@wp.pl

\begin{abstract}
The article discusses a multifactorial approach to the restoration of muscle volume and rehabilitation of football players after sports injuries, which includes the implementation of electric myostimulation in a magnetic field in combination with the effect of electromagnetic radiation of the visible or infrared spectrum on muscles and the area of injury. Comparative studies were carried out in two groups of footballers in rehabilitation after ankle injury rehabilitation. The medical rehabilitation of the players of the 1st group was carried out according to the protocol approved in the center: the MIT-FM apparatus, the protocol for the implementation of rehabilitation provides for the implementation of drug treatment and physiotherapeutic procedures based on the combined use of therapy with electromagnetic waves of the red, blue and infrared spectral range with a power of $50 \mathrm{~mW}$ in a pulsed magnetic field of intensity $30 \mathrm{mT}$ and a pulse repetition rate of $9.4 \mathrm{~Hz}$.

In group 2, the rehabilitation of footballers after injuries of the lower extremities was carried out according to the protocol developed by the authors: sequential connection of the rehabilitation protocol of the first group and combined magneto-photo electric myostimulation of muscles with myotonic impulses, with a pulse repetition rate of $9.4 \mathrm{~Hz}$. The repetition period of the packs of impulses is 8 seconds with the duty cycle of repetition of the packs of impulses 2 . The current strength was set individually for each patient - until the appearance of visible muscle contractions.

Muscle photostimulation was performed with electromagnetic radiation of red (wavelength $0.63 \mu \mathrm{m}$, power $30 \mathrm{~mW}$ ), blue (wavelength $0.45 \mu \mathrm{m}$, power $30 \mathrm{~mW}$ ) and infrared (wavelength $0.75 \mu \mathrm{m}$, power 50 $\mathrm{mW}$ ) spectral ranges in constant magnetic field (intensity $30 \mathrm{mT}$ ).
\end{abstract}


The first electrode is placed on the muscle's innervation zone. The second electrode provides a combined effect of electrical impulses and optical flux in a constant magnetic field on the abdomen of the muscle according to the labile technique.

The time of one procedure was 40 minutes. The number of procedures for a course of treatment is 15.

As a result, the analysis of the data obtained (assessment of the quality of life according to the extended table SF-36) revealed a positive dynamics of clinical manifestations in both groups. The main result of the research is the development of a protocol for the rehabilitation of football players after injuries of the lower extremities based on the use of drug treatment, physiotherapy procedures based on the combined use of therapy with electromagnetic waves of the blue and infrared spectrum in a constant magnetic field in combination with muscle electrostimulation, which has a higher level rehabilitation potential versus applicable footballerI rehabilitation protocols.

Key words: sports injury, muscles, electrical myostimulation, magnetic therapy, electromagnetic wave therapy.

\section{Introduction}

Football is not only one of the most popular sports in the world, but also one of the most traumatic sports. Collisions between players or accidental incorrect movements of players during the game can lead to serious injury.

1.The knee and ankle joints and muscles are most prone to injury [1]. Muscle tissue is a significant part of a football player's body weight - it accounts for $52-59 \%$ of the lean body mass. The musculoskeletal system of football players, as a result of constant training and participation in sports competitions, is in an overstrained state; this explains the high prevalence of injuries and diseases of the neuromuscular synapse and muscles (according to the international classification of diseases, the group G70-G73).

2.As a rule, footballers are injured from kicks during the game, landings with leg twists or sudden stops. The most common injuries for football players are associated with:

3.Rupture of the medial meniscus - the cartilaginous layer between the articular surfaces of the femur and tibia. The meniscus absorbs shock and distributes the load to the knee. The medial meniscus, in contrast to the lateral, is attached to both the articular capsule and the tibia itself. This variant of the anatomical position makes it inactive, which leads to a rupture of the meniscus when the leg is loaded with rotation of the lower leg. This injury is often associated with a sprain of the knee ligaments.

4. Tears or sprains of the ligaments that stabilize the knee joint. These ligaments have a high degree of tension to prevent the joint from moving. Their damage is accompanied by severe pain syndromes. The anterior cruciate ligament is most commonly affected. It prevents the lower leg from moving forward in relation to the thigh. Its rupture occurs from a blow to the knee, or from twisting of the knee joint during landing on the leg. Injuries to the medial collateral ligament often occur during twisting of the lower leg..

5.Deformation of the hamstring, which occurs when the foot is excessively turned inward.

6.Damage to the muscles of the lower leg occurs during the ball, fast running. In this case, the vessels and nerve fibers of the lower leg are also damaged.

7.Ruptured ankle ligaments - such an injury can be repeated several times in one athlete. Most often, the lateral ligaments of the ankle are damaged, resulting in an inversion of the foot. Also, with a sharp twisting or twisting of the foot inward, the anterior and posterior talofibular ligaments are affected. These footballer injuries have long-term consequences in the form of cartilage detachment in the talus dome.

8.All these injuries require a fairly long-term rehabilitation and, as a rule, are accompanied by pain syndromes, a decrease in muscle mass, and an increase / occurrence of anxious depression.

The timing of football players' recovery after injuries depends on timely diagnosis, assessment of the rehabilitation potential, a rehabilitation program with the selection of physical therapy exercises and physiotherapy procedures aimed at restoring muscle mass, strengthening muscles and ligaments, restoring the functional memory of the neuromuscular system after rehabilitation measures.

The use of only the medicament treatment methods often does not provide the desired positive 
effect and, at the same time, often causes side effects. The most effective way to treat this group of diseases is the use of physiotherapeutic methods of treatment.

Currently, several methods of physiotherapeutic treatment of diseases of the neuromuscular synapse and muscles are known. For example, treatment by pulsed electrophoresis of analgesic or anti-inflammatory drugs [2], magnetic laser and ultrasound therapy [3-8].

The main disadvantages of the existing protocols for the rehabilitation of football players are the consistent use of various physical factors for the rehabilitation of diseases of the neuromuscular synapse and muscles after injuries, without taking into account the physiological and functional characteristics of the injury.

\section{Objective}

Creation of a multifactorial approach in the development of protocols for the rehabilitation of football players after sports injuries, taking into account the individual psycho-functional and anatomical characteristics of football players based on the use of innovative technologies of physiotherapy and kinesis therapy.

\section{Methods}

The task is achieved by the fact that in the known methods of physical and medical rehabilitation of football players after professional injuries are carried out according to two rehabilitation protocols.

Procedure / Test protocol / Skill test trial / Measure / Instruments. The first protocol for the implementation of rehabilitation provides for the use of drug treatment and physiotherapy procedures based on the combined use of muscle electrical myostimulation [4-9] and therapy with electromagnetic waves of the red, blue and infrared spectrum in a constant magnetic field. Muscle electric myostimulation was performed with myotonic impulses, the pulse repetition rate was $9.4 \mathrm{~Hz}$. The repetition period of the packs of impulses is 8 seconds with the duty cycle of repetition of the packs of impulses 2 .

The second protocol for the rehabilitation of footballers after injuries of the lower extremities is performed as a sequential connection of the first protocol of rehabilitation and physical exercises in combination with two-channel electrical neurostimulation of the extremities.
The choice of the optical spectrum of electromagnetic radiation of waves for carrying out procedures is based on the anatomical structure of the muscle fiber and the results of experimental studies [9$11]$.

Stimulation of photochemical reactions in sarcolemmas and myofibrils of muscles is performed by a red stream of light (wavelength 0.63-0.65 microns), in mitochondria by a blue stream of light (wavelength 0.45 microns), infrared flux of electromagnetic radiation (wavelength $0.78-0.90 \mu \mathrm{m}$ ) stimulates anti-inflammatory processes inside the muscle tissue.

The procedures were carried out 5 times a week. 15 procedures were prescribed for the rehabilitation course. The time of one procedure was 40 minutes. Physical exercises were performed after the main procedure in 10 minutes for 20 minutes.

Participants. To assess the effectiveness of the proposed multifactorial approach in the rehabilitation of the muscles of football players after sports injuries, comparative clinical observations were carried out on a group of 12 football players, who were selected on the basis of 4 criteria: the presence of an injury and a change in the volume of muscle mass of at least $10 \%$; age 25-35 years; written consent of the football player and coach to participate in the research; no contraindications for physiotherapy treatment. The patients were randomly divided into 2 groups of 6 football players in each group.

The studies were carried out on the basis of a licensed medical center.

Medical rehabilitation of the players of the 1st group was carried out according to the protocol approved by the center. Procedure parameters: the "MIT-CM" apparatus, rehabilitation protocol provides for the use of drug treatment and physiotherapy procedures based on the combined use of therapy with electromagnetic waves of the red, blue and infrared spectrum with a power of $50 \mathrm{~mW}$ in a pulsed magnetic field with strength of $30 \mathrm{mT}$ and a pulse repetition rate of $9.4 \mathrm{~Hz}$.

In group 2, the rehabilitation of footballers after injuries of the lower extremities was carried out according to the protocol developed by the authors: as a sequential connection of the rehabilitation protocol of the first group and a combined magnetic-photo and electric myostimulation of muscles with myotonic impulses, with a pulse repetition rate of $9.4 \mathrm{~Hz}$. The repetition period of the packs of impulses is 8 seconds 
with the duty cycle of repetition of the packs of impulses 2 . The current strength was set individually for each patient - until the appearance of visible muscle contractions.

Muscle photostimulation was performed with electromagnetic radiation of red (wavelength $0.63 \mu \mathrm{m}$, power $30 \mathrm{~mW}$ ), blue (wavelength $0.45 \mu \mathrm{m}$, power 30 $\mathrm{mW}$ ) and infrared (wavelength $0.75 \mu \mathrm{m}$, power $50 \mathrm{~mW}$ ) spectral ranges in constant magnetic field (intensity 30 $\mathrm{mT})$.

The first electrode is placed on the muscle's innervation zone. The second electrode provided a combined effect of electrical impulses and optical flux in a constant magnetic field on the abdomen of the muscle according to the labile technique.

The time of one procedure was 40 minutes. An example of a group 2 patient procedure is shown in Figure 1.

The study model included a clinical and neurological assessment of patients and an assessment of the quality of life using the SF-36 questionnaire [12].

Data collection and analysis / Statistical analysis. Analysis of the results of the study shows that at the beginning of the experiment between students of the control and experimental groups there were no significant differences $(p>0.05)$.

\section{Results}

The result of the proposed solution is an increase in the efficiency and reduction of the treatment time due to the combined use of electric myostimulation, causing muscle contraction, stimulation of photochemical processes in the muscle based on the use of electromagnetic radiation, visible and infrared ranges of the spectrum, improvement of microcirculation and fluidity of fluid media in the muscle based on the use of a magnetic field.

A new result in this work is a study of the effectiveness of the protocol for the rehabilitation of footballers after injuries of the lower extremities based on the use of drug treatment and carrying out physiotherapeutic procedures based on the combined use of therapy with electromagnetic waves of the red, blue and infrared spectrum in a constant magnetic field in combination with muscle electrostimulation and sequential performing physical exercises in combination with two-channel electrical neurostimulation of the extremities.

The results of the research are presented in Figure 2.

Fig. 2. The results of assessing the quality of life of football players before and after rehabilitation using the expanded SF-36 questionnaire

Where, PF - Physical functioning, RP - Role (physical) functioning, VR - Pain, GH - General health, VT - Vitality, V - muscle volume, RE - Emotional functioning, $\mathrm{MH}$ - Psychological health, $\mathrm{T}$ - Terms of rehabilitation.

\section{Discussion}

PTo assess the results of rehabilitation measures for each group at the time of the beginning of the procedures and after the full course of procedures, the SF-36 table was used, which was supplemented with 2 sections: the volume of the gastrocnemius muscle from the side of the injury and the rehabilitation time of football players. The resulting average values for all indicators were rounded to the nearest whole value.

Physical Functioning (PF) - at the beginning of rehabilitation in the first group was 51 points in the second - 52 points. After the rehabilitation measures in the first group, this indicator was 86 points, in the second group - 98 points.

Role-Physical Functioning - RP - at the beginning of rehabilitation in the first group was 63 points in the second - 65 points. After the rehabilitation measures in the first group, this indicator was 92 points, in the second group 99 points.

The intensity of pain (Bodily pain - BP) and its effect on the ability to carry out daily activities, including work around the house and outside the home. Before the start of the rehabilitation program, the intensity level in both groups was approximately 45-47 points, after the rehabilitation measures in group 1, the intensity of pain was 89 points and 97 points in the second group. Lower scores on this scale indicate that pain significantly limits the patient's activity.

General health $(\mathrm{GH})$ - patients' assessment of their state of health at the moment and after the implementation of rehabilitation measures. At the time of the beginning of rehabilitation measures, the general state of health of the football players was assessed at 
the level of 75-77 points, after the course of rehabilitation procedures, the assessment of the general state of health, according to the participants in the study, was 83 points in the first group and 95-96 points in the second group. The lower the score on this scale, the lower the health score.

Vitality (VT) means feeling full of strength and energy, or, on the contrary, exhausted. Before the rehabilitation measures, the general state of vital activity of athletes was assessed at the level of 67-68 points; after the course of rehabilitation procedures, the subjective assessment of vital activity according to the participants in the study was 83 points in the first group and 95 points in the second group. Low scores indicate patient fatigue, decreased vitality.

Muscle volume (V), the change in muscle volume in comparison with the volume of the corresponding muscle of the non-injured side is estimated before the start of rehabilitation measures. Muscle volume was measured along the circumference around the non-injured limb in the area of the symmetrical injured muscle. Before the rehabilitation measures, the average value was $48 \mathrm{~cm}$ (points), after the course of rehabilitation procedures it was $42 \mathrm{~cm}$ (points) in the first group and $51 \mathrm{~cm}$ (points) in the second group. Low rates correspond to a decrease in muscle mass without specialized rehabilitation.

Social Functioning (SF), defined by the degree to which a physical or emotional state limits social activity (communication). Before the rehabilitation measures, the social functioning of athletes was assessed at the level of 67-68 points, after the course of rehabilitation procedures, the assessment of social functioning in the opinion of the study participants was 83 points in the first group and 95 points in the second group. Low scores indicate a significant limitation of social contacts, a decrease in the level of communication due to deterioration in physical and emotional state.

Role functioning due to the emotional state (Role Emotional - RE) involves an assessment of the degree to which the emotional state interferes with the performance of work or other daily activities (including a long time, reduced volume of work, decreased quality, etc.). Before the rehabilitation measures, the role functioning of athletes was assessed at the level of 67-68 points; after the course of rehabilitation procedures, the assessment of role functioning according to the participants in the study was 83 points in the first group and 95 points in the second group. Low scores on this scale are interpreted as a limitation in performing daily work due to deterioration in the emotional state.

Mental Health $(\mathrm{MH})$ characterizes the mood, the presence of depression, anxiety, a general indicator of positive emotions. Before the rehabilitation measures, the mental health of football players was assessed at the level of 61-62 points, after the course of rehabilitation procedures, the assessment of mental health according to the participants in the study was 88 points in the first group and 97 points in the second group. Low rates indicate the presence of depressive, anxious experiences, mental distress.

According to the research results, the authors received six patents of Ukraine [13-18].

In the course of the rehabilitation, the optimal terms of rehabilitation were determined on the basis of the protocols proposed by the authors - 15 procedures with a frequency of 5 times a week with a break on Wednesday and Sunday. The total rehabilitation time in the main (2) group was 21, the day in the control (1) group, the rehabilitation period averaged 28 days [1927].

\section{Conclusion}

The results of our study revealed a positive dynamics of clinical manifestations in both groups of patients.

After analyzing the data obtained (assessment of the quality of life according to the modified table SF-36), muscle volume, reduction of the rehabilitation time for football players, it was found that the protocol for the rehabilitation of football players after injuries of the lower extremities based on the use of drug treatment, physiotherapy procedures based on the combined use of electromagnetic wave therapy of the blue and infrared ranges of the spectrum in a constant magnetic field in combination with muscle electric myostimulation is the more effective method of rehabilitation in comparison with only drug treatment.

\section{Compliance with Ethical Standards}

Tests in patients are conducted in accordance with positions of Helsinki Declaration 1975, revised and complemented in 2002, and directive of National Committee on ethics of scientific researches. During realization of tests from all participants the informed consent is got and used all measures for providing of anonymity of participants.

\section{Informed Consent}


Informed consent was obtained from all individual participants included in the study. All subjects of the institutional survey gave consent for anonymized data to be used for publication purposes.

\section{Conflict of Interest}

The authors declare that they have no conflict of interest.

\section{References}

1. Sportivnaya travma: diagnostika i lecheniye [Sports injury: diagnosis and treatment]. P. Makmaon. Nauchnyy redaktor V.V. (2011). Uyba. Translated from English. M. «Praktika», 366 p. (Russian).

2. Samosyuk, I.Z., Chukhraiev N.V., Samosyuk N.I., Chukhraieva Ye.N. (2012). Elektroterapiya i elektropunktura v meditsinskoy reabilitatsii, fizioterapii i kurortologii [Electrotherapy and electropuncture in medical rehabilitation, physiotherapy and balneology]. K., 291 p. (Russian).

3. Samosyuk I.Z., Malyuta V.I., Chukhraiev N.V. (2016). Lecheniye bolevykh sindromov [Treatment of pain syndromes]. Vein. NMAPE named after P.L. Shupik, Educational establishment of physical and rehabilitation medicine. 224 p. (Russian).

4. Samosyuk I.Z., Malyuta V.I., Chukhraiev N.V., Shmorgun A.A. (2019). Primeneniye ul'trazvukovoy i magnitolazernoy terapii $\mathrm{v}$ klinicheskoy i sportivnoy meditsine [Application of ultrasound and magnetic laser therapy in clinical and sports medicine]. Kiev, 376 p. (Russian).

5. Chukhraiev N.V., Vladimirov A.A., L.Vilcahuaman, W. Zukow, Samosyuk N.I., Chukhraieva E., Butskaya L.V. Combined application of ultrasonic waves, magnetic fields and optical flow in the rehabilitation of patients and disabled people. Kiev Shupyk National Medical Academy of Postgraduate Education, University of Radom High School, SCM «Medical Innovative Technologies. 2016. 304 p.

6. Chukhraiev N., Vladimirov A., Vilcahuaman L., Zukow W., Samosyuk N., Chukhraieva E., Butskaya L. (2017). Application of ultrasonic waves, magnetic fields and optical flow in rehabilitation. Kiev Shupyk National Medical Academy of Postgraduate Education, University of Radom High School, SCM «Medical Innovative Technologies». 324 p.

7. Samosyuk I.Z., Malyuta I.V., Chukhraev N.V. (2018). Meditsinskaya i psikhologicheskaya reabilitatsiya postinsul'tnykh bol'nykh [Medical and psychological rehabilitation of post-stroke patients]. Radom. Radomska Szkoła Wyższa w Radomiu. 527 p. http://dx.doi.org/10.5281/zenodo.1169332
8. Chukhraev N.V. Korobov A.M., Possokhov N.F., Gorbunov O.V. (2014). O deystvii nizkointensivnogo elektromagnitnogo izlucheniya vidimogo diapazona spektra i magnitnogo polya na vosstanovleniye povrezhdennykh perifericheskikh nervov eksperimental'nykh zhivotnykh [On the effect of low-intensity electromagnetic radiation in the visible range of the spectrum and a magnetic field on the restoration of damaged peripheral nerves in experimental animals]. Materials of the XXXXI International Scientific and Practical Conference. Application of lasers in medicine and biology. pp. 4142.

9. Posokhov N.F. Chukhraiev N.V., Gorbunov O.V., Korobov A.M., Mikhailov A.I. (2014). Rezul'taty eksperimental'no-morfologicheskogo issledovaniya regeneratsii perifericheskogo nerva pod vliyaniyem krasnogo izlucheniya svetodiodov i impul'snogo magnitnogo polya [The results of an experimentalmorphological study of peripheral nerve regeneration under the influence of red radiation of LEDs and a pulsed magnetic field]. Photobiology and photomedicine. International scientific and practical journal. XII(3.4):71-78.

10. Chukhraev N.V., Zukow W., Unichenko A.V., Butskaya L.V., Gres O.O. (2019). Multidisciplinary approach in the treatment of spin diseases. Journal of Education, Health and Sport. 9(1):294-307.

DOI http://dx.doi.org/10.5281/zenodo. 2553467

11. Terehov G.V., Chukhraeva O.M., Savytska I.M., Kostylev M.V., Malyuta V.I., Geylenko O.A., Chukhraiev M.V. (2019). [Investigation of the impact of photostimulation and healing of postoperative wounds in experiment]. Klinicheskaia Khirurgiia, 86(9):50-53. https://doi.org/10.26779/25221396.2019 .09 .50

12. Lysenyuk VP., Samosyuk I.Z,. Fisenko L.I. and others. (2007). [Medical rehabilitation: modern standards, tests, scales and performance criteria. Low-intensity resonance physiotherapy and its application in rehabilitation medicine]. Manual. K.: "SMC "Medinteh", $180 \mathrm{p}$.

13. PU №117125. [Barocomplex for the treatment of diseases of the lower extremities]. Chukhraiev N.V., Malyuta V.I., Chukhraieva E.N., Fedul Vladislav. Publ. 12.06.2017, bul. №11/2017.

14. PU №117126. [Vortex footbath]. Chukhraiev N.V., Malyuta V.I. Publ. 12.06.2017, bul. №11. 
15. PU №118414. [Vortex hydromassage footbath]. Chukhraiev N.V. Published on 08/10/2017, blvd. №15.

16. PU №123018. [The device for psychosomatic correction of diseases of the lower extremities in athletes]. Chukhraiev N.V.; Malyuta V.I.; Mironov L.A.; Shmorgun O.O.; Zhuchka A.V., Abolfathi Mehdi Moses; Unichenko A.V. Publ.12.02.2018, blvd. №3.

17. PU №144243. [A method of treating diseases of the neuromuscular synapse and muscles]. Chukhraiev M.V.; Chukhraieva O.M.; Malyuta V.I.; VI box; Zhuchka A.V.; Wise O.I.; Unichenko A.V. Publ. 25.09.2020, bul. №18.

18. PU №144244. [A method of treating dorsopathy]. Chukhraiev M.V.; Chukhraieva O.M.; Maluta V.I., Alexander Bitson; Wise O.I.; Pilyuyko V.V.; Tsits G.D.; Unichenko A.V. Publ. 25.09.2020, bul. №18.

19. Gushcha, S. G., Oleshko, A. Y., Bakholdina, E. I., Badiuk, N. S., \& Zabolotna, I. B. (2021). Correction of disturbances of functional activity of the central nervous system in rats with the post-traumatic stress disorder model using remedy with a high magnesium content. PharmacologyOnLine. 1, 12-19.

20. Shmakova, I. P., Shapovalova, H. A., Mokienko, A. B., Badiuk, N. S., Babienko, V. V., \& Gushcha, S. G. (2021). Mineral waters as a part of sanatorium-resort rehabilitation for children in remission of oncological diseases. PharmacologyOnLine. 1, 156-162.

21. Gozhenko, A. I., Korshnyak, V. A., Nasibullin, B. A., Savytskyi, I. V., Gushcha, S. G., \& Badiuk, N. S. (2021). The involvement of brain specific proteins in the pathogenesis of the consequences of closed pulmonary cranial injury. PharmacologyOnLine. 1, 6-11.

22. Shapovalova, H., Shmakova, I., Mokiienko, A., Gushcha, S., \& Plakida, A. (2021).
Substantiation of the additional prescription of magnetotherapy in the complex of rehabilitation of children with concomitant diseases of the nervous system during remission of cancer. Balneo and PRM Research Journal. 12(1):73-76.

23. Puhlik, S. M., Andreev, A. V., Gushcha, S. G., Tagunova, I. K., Volyanska, V. S., Balashova, I. V., \& Badiuk, N. S. (2021). Experience with the use of oral probiotic Streptococcus salivarius K12 for the prevention of recurrence of pharyngotonsillar episodes. PharmacologyOnLine. 1, 120-124.

24. Babov, K., Nikipelova, O., Sydorenko, O., Gushcha, S., Zabolotna, I., \& Zukow, W. (2021). Grounds for the establishment of a state-owned resort on the territory of the city of Morshyn, Lviv region, Ukraine. Ecological Questions, 32(1): 1-15.

25. Strus, O., Babov, K., Gushcha, S., Polovko, N., Nasibullin, B., \& Polshchakova, T. (2020). Toxicological and Biological Assessment of the Effect of Sapropel of the Prybych Lake during Cutaneous Application in Rats. Open Access Macedonian Journal of Medical Sciences, 8(A): 633-638.

26. Bilas, V., Popadynets', O., Flyunt, I.-S., Sydoruk, N., Badiuk, N., Gushcha, S., Zukow, W., Gozhenko, A., \& Popovych, I. (2020). Entropies of thymocytogram, splenocytogram, immunocytogram and leukocytogram in rats are regulated by sex and the neuroendocrine parameters while regulates immune parameters. Journal of Education, Health and Sport, 10(7): 266-288.

27. Kuznetsova, H. S., Kuznetsova, K. S., Olenovych, O. A., Gozhenko, O. A., Kuznetsov, S. H., \& Gozhenko, A. I. (2018). The desquamation of the endothelium due to normalization of glycemia decreases in patients with diabetes mellitus. PharmacologyOnLine, 2: 74-81. 


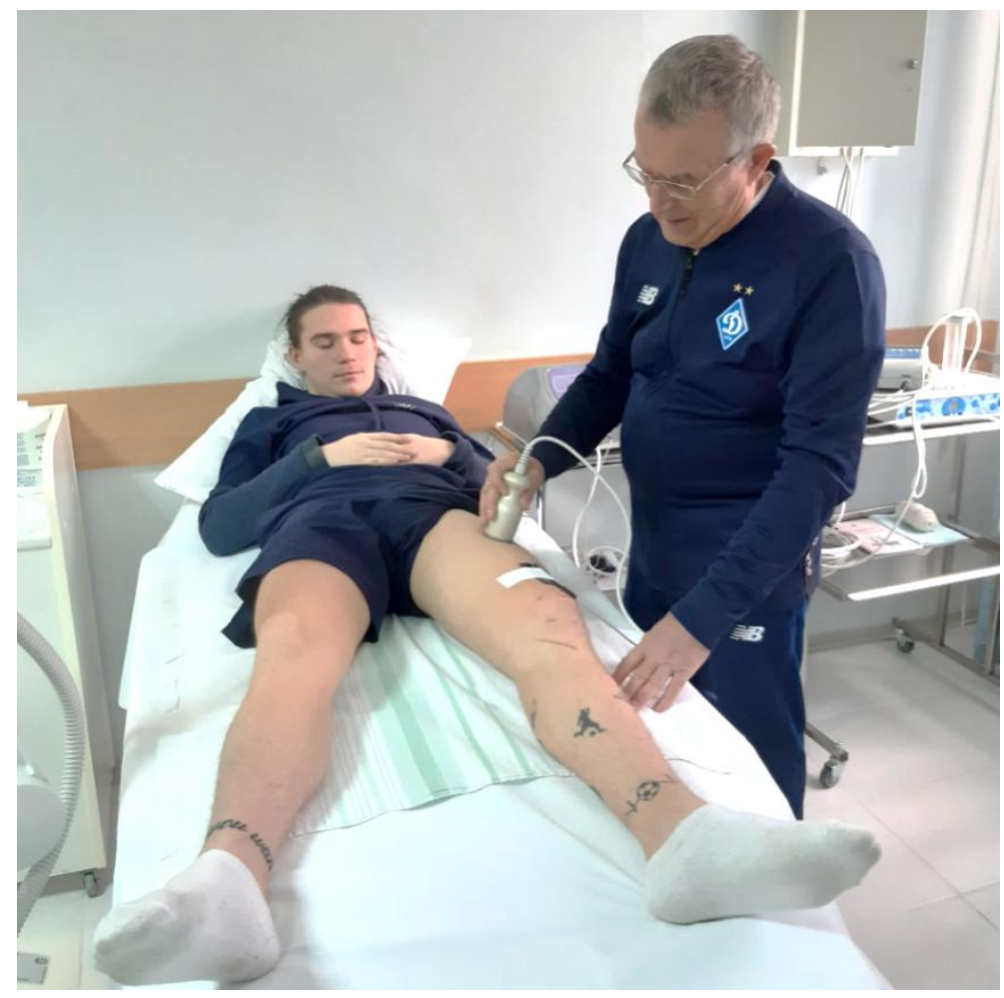

Fig. 1. An example of the procedure for a patient of group 2 (Photo by the author). 


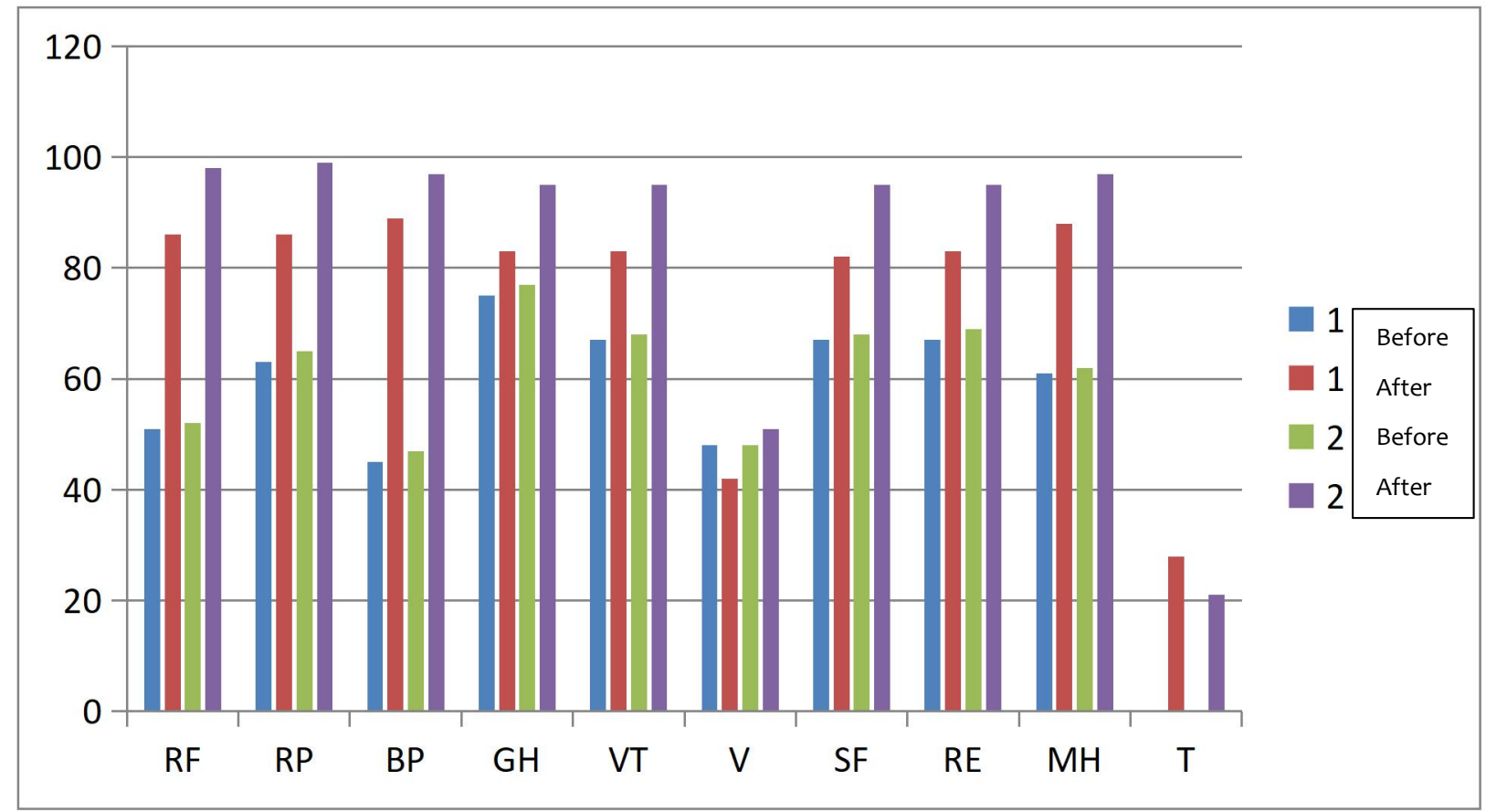

Fig. 2. The results of assessing the quality of life of football players before and after rehabilitation using the expanded SF-36 questionnaire

Where, PF - Physical functioning, RP - Role (physical) functioning, VR - Pain, GH - General health, VT - Vitality, V muscle volume, RE - Emotional functioning, $\mathrm{MH}$ - Psychological health, T - Terms of rehabilitation. 